\title{
COMPARING FORMS OF NEW HIGHER EDUCATION ORGANISATIONS AT START-UP
}

\begin{abstract}
In this article, we investigate three recently established entrepreneurial organisations created to deliver education and training to new audiences of learners at a distance. Each of the organisations - the University of Michigan's Academic Outreach Program, the University Center at Northwestern Michigan College, and the Michigan Virtual Automotive College - is involved in multiple complex partnerships with internal and external entities, including government, industry, and education. Paying particular attention to the structures, strategies, and processes of these organisations, we argue that their emergence signals the evolution of a postsecondary knowledge industry in which permeable boundaries, new competitors, and market sensibilities are converging to challenge the fundamental nature of postsecondary education.
\end{abstract}

\section{INTRODUCTION}

Will an industry based on the ubiquity, relevance, and immediate application of knowledge create exciting possibilities and new challenges for postsecondary education? New organisations are gambling that innovative thinking will place them at an advantage in an environment in which the competitors are often well financed and technologically sophisticated. This paper examines three higher education organisations whose attempts to establish themselves within the emerging knowledge industry illustrate innovative approaches to strategy, structure and processes during organisational start-up.

\section{An emerging postsecondary knowledge industry}

Societal forces are causing profound changes in the nature of postsecondary education. New diverse demands such as globalisation, demographic changes, technology innovation, and resource constraints may cause current postsecondary institutions to be reshaped and redirected (Peterson \& Dill 1997). Peterson and Dill claim that such changes are propelling postsecondary education toward a nascent industry model in which the core technologies, new organisational entrants, customers, new powerful suppliers, and more intense competition will be the driving forces behind 
the need for innovative thinking and action. In recent years, some evidence has surfaced to illustrate the points advanced by Peterson and Dill. It is suggested here that a postsecondary knowledge industry has begun to take shape as evidenced of late in new forms of postsecondary institutions that rely on multiple partners to deliver education and training to learners at a distance. Understanding the changes and pressures caused by the knowledge industry transition may best be observed at the interface of environment and the institution. A key question concerns how postsecondary institutions are organising themselves to accomplish the tasks needed to sustain viability in the new millennium.

\section{New organisational forms emerge}

The entrepreneurial organisation that is created to link the institution's internal and external environment represents an attempt among colleges and universities to effectively initiate and develop the growing linkages between higher education and its various audiences. We conceive of these new organisational forms as those that are significantly involved in multiple internal and external relationships with key constituents, including learners, corporate partners, governments, and other colleges and universities and which attempt to move quickly to seize market opportunities. Due to their recent emergence, there is only limited understanding of the evolution and start-up issues associated with entrepreneurial, boundaryspanning organisations or the manner in which they reflect broader industry characteristics. This descriptive information can yield important insights regarding the interface between higher education and its multiple environments and, more specifically, clarify the means by which colleges and universities are organising to respond to and shape future market opportunities.

\section{Defining this emerging organisational type}

Certain characteristics support the uniqueness of an organisational form that is entrepreneurial and boundary spanning, particularly during the start-up phase. These new organisations are often responsible for radical innovations, in the sense that they are not just dealing with slight modifications to or improvements in products and processes. Rather, they are moving into new industries, using new technologies, marketing and delivering new products and services, and utilising extensive networks of business partners to meet strategic objectives. In short, such organisations are exploring new frontiers and market opportunities that extend the role, reach, and mission of postsecondary institutions. 


\section{Research questions}

In this study we sought answers to three questions:

1. How do these three start-up organisations inform the nature of boundary conditions in the evolving knowledge industry?

2. How do the dynamics of the knowledge industry influence the strategy, structure, and processes of newly created higher education organisations? and

3. How do organisational managers respond to the influences of the knowledge industry?

The next section of this paper addresses the research questions by providing descriptive accounts of three new organisations struggling with the entrepreneurial, boundary-spanning role. Part one sets a context for the case and considers the organisation's historical development. Part two addresses the organisation's form, specifically the strategy, structure and processes, meant to respond to and enact the postsecondary knowledge industry environment. Finally, part three considers the organisations' boundaries and their relationship to the emerging knowledge industry.

\section{Case Study of Academic Outreach Programme, UNIVERSITY OF MICHIGAN}

\section{Context}

In 1995, the University of Michigan launched the Academic Outreach (AO) programme to develop distance learning and extension programmes that complemented its campus-based academic mission. Driven largely by the motivations of the University's President and the Dean of AO, the department was predicated on the impending competitive threat from nontraditional knowledge providers in servicing the needs of life-long learners or organisations.

Since its inception, AO has significantly grown in size from three full time employees to approximately 35 employees. Included in this number are several graduate student research assistants and other part-time employees. It has launched several pilot programmes with schools and colleges at the University and with external partners, and it has constructed a facility for faculty to experiment with various technologies and to apply them to their research and teaching.

The arrival of a new administration in January 1997 signaled a change in the attitude of the University towards outreach activities. As the new President supports the traditional residential model for the University, it 
remains unclear to what extent his administration will support the AO initiative. Still, AO intends to achieve five objectives that support outreach programmes at the University. The five goals $\mathrm{AO}$ is currently pursuing include (AO Web site):

- increase the distinction of the University of Michigan.

- build the University of Michigan extended learning environment.

- implement distance learning strategies.

- provide leadership in utilising information technology in higher education.

- create effective partnerships.

\section{Organisational form of academic outreach}

\section{Structure}

$\mathrm{AO}$ is a department at the University of Michigan that reports directly to the Office of the Provost. Its organisational structure is flat, with a Dean for $\mathrm{AO}$ overseeing two programme managers and a number of other staff. The AO Dean is responsible for institution-wide leadership and coordination of academic outreach activities. The Director of Residential and Research University Programs is principally responsible for the expansion of spring and summer programme offerings on campus, development of distance education programmes, and is helping to design the infrastructure of the virtual university. The Director of Program Development identifies and implements projects that enable AO to extend the boundaries of the University. Such programmes include partnerships with educational, corporate, government, or nonprofit entities. The rest of the AO staff includes a programme coordinator, administrative support personnel, media and technical specialists, and several graduate student research assistants. Figure 1 illustrates the current $\mathrm{AO}$ organisational structure.

Although the AO organisational structure is comprised of managers with defined responsibilities, it is clear that the department has a project based organisational structure. That is, human resources are allocated to projects as they emerge. One manager labeled the structure of AO as 'very organic' and that it has grown based on the 'skills and connections of people who populate it.' For example, the Director of Program Development concentrated a majority of his efforts on the automobile industry because of personal relationships at automobile companies. One outcome of these contacts has been the development of an off-campus academic programme co-sponsored by Ford Motor Company and the United Auto Workers. 'I move towards my contacts in industry and my interests in industry when I'm putting together new sorts of things. It's the way that 


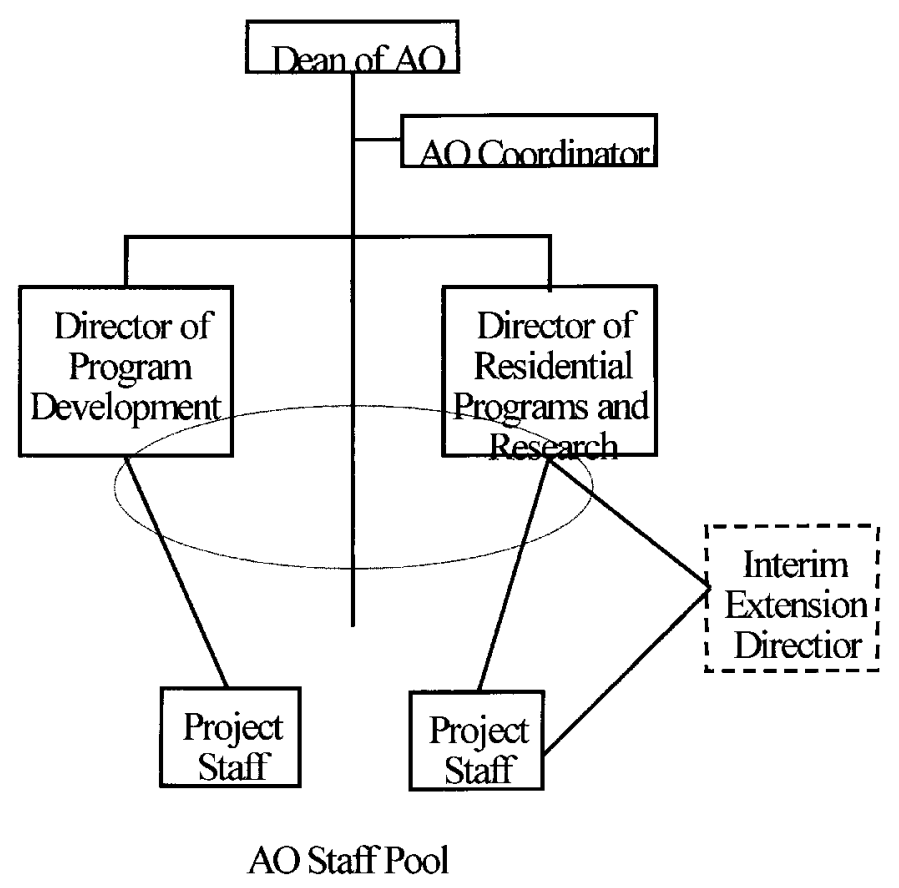

Figure 1. Academic Outreach Organizational Structure.

I am, so I moved toward them in programme development', explained the Director of Program Development.

The result, according to one staff member, has been 'a laundry list type of organisation with a variety of discrete projects.' It is difficult, therefore, to map out an organisational structure. The project based approach creates an environment in which staff members are shifted to different tasks as needed. More than one staff member commented on how they only vaguely knew the responsibilities of several people in $\mathrm{AO}$, and new faces sometimes appeared in the office without explanation.

\section{Strategy}

To achieve its strategic goals, $\mathrm{AO}$ has emphasised managing and nurturing the internal constituencies of the University while at the same time creating relationships with external partners. These two strategies are intended to complement one another by building support inside the University for AO initiatives while concurrently piloting outreach activities to gain the expertise necessary to develop AO's competencies.

AO has sponsored several symposia and workshops for the campus community. At these functions there have been demonstrations of distance learning technologies, speakers on virtual universities, and discussions on 
how faculty can utilise technology in their teaching and research. AO has also invested in the construction of a facility where faculty can experiment with various technologies and applications. The facility provides faculty with an environment in which to experiment with the technology and build capabilities that will eventually support academic outreach initiatives. Another important strategy has been building relationships with the University's academic deans. AO has extended this strategy by co-sponsoring several pilot programmes with schools and colleges that have indicated a willingness to utilise its services. Such programmes have included faculty training courses and the development and delivery of online courses to a local manufacturing organisation.

\section{Processes}

The Director of Program Development admits that he is drawn to projects where partners can contribute funds or human resources because that security increases the chances for success. He says that AO probably won't participate in a co-sponsored programme if partners don't have money. In some cases the Dean suggested that AO contribute resources and expertise to assist a school or college to make their project successful. It is hoped that by encouraging participation an internal network of support will evolve. He maintains that such an approach is integral to AO's success because the ownership of the project will exist within the traditional structure of the institution rather than with $\mathrm{AO}$.

Who AO partners with is largely dictated by the personal relationships that the Director for Program Development has with people or with organisations. For example, he had numerous contacts in a major local industry and with an international federation. In both cases he used his personal contacts as a basis for those organisations to share in the development of pilot projects. The partners, therefore, were more determined by previous association and by a commitment of resources than whether they necessarily matched the outreach needs of academic programmes.

Because the structure of the organisation is project based, there is a lack of communication and teamwork in AO. One manager likened the situation to a bowling alley, with each of the lanes representing individual projects with little or no cross-over between the lanes (projects). There has been very little attempt to communicate how these various projects are interconnected and relate to AO's mission. This lack of communication and understanding of AO's objectives makes the roles of individuals unclear.

It appears therefore that the nature of the work processes in this start-up organisation have been highly determined by the individual working styles of various AO staff. While projects have materialised, the 'organic' nature 
of this approach causes these programmes to be somewhat disjointed and thus AO appears to be moving (or not moving) in a variety of unrelated directions.

\section{Boundary conditions}

Based upon what we know about the structure, strategy, and processes of $\mathrm{AO}$, it is clear that both internal and external boundaries influence this organisation. AO appears to be very sensitive to the internal boundaries or constituents as it continues to try and obtain institutional support. The university's heavy emphasis on research productivity creates an environment that is not compatible with distance learning or academic outreach. Managers maintain that given this internal environment it is appropriate that AO's strategies complement internal constituents rather than compete against them. Their strategic plan is characterised by projects that will build a support services network for the University's schools and colleges. The external boundaries of AO are also quite permeable. Indeed, due to the style of some of its managers, many AO projects are determined by external organisations.

One would expect that the rapid changes in the global economy and the demand for knowledge services would make external boundaries permeable to an EBSO. In the case of AO, however, its contextual implications of being a unit at a major research university indicates internal boundaries may be just as significant.

\section{Summary}

$\mathrm{AO}$ appears to be a start-up organisation that is having trouble establishing its identity. It recognises the trends in the knowledge industry and how they may impact the University. At this time, however, AO appears to be a series of loosely connected experiments that are not cohesively moving the University towards a successful outreach programme. Furthermore, the complexities of a major research university, including its fairly autonomous schools and colleges, its slow moving bureaucracy, and the uncertain support of University leaders suggests that $\mathrm{AO}$ is a start-up organisation with an internal environment that is an impediment to its success.

\section{Case Study of Northwestern Michigan College UNIVERSITY CENTER}

\section{Context}

The University Center is a partnership between Northwestern Michigan College, a comprehensive two year community college, 12 four-year 
colleges and universities, and local community secondary schools. The partnership allows students in northwest Michigan to complete their third and fourth years of select baccalaureate and graduate programmes within their community. The courses are taught using two-way interactive television, which allows faculty members at the host institution to reach students in northwest Michigan. Other courses are taught by faculty who travel to the Traverse City area.

The University Center vision was developed through a collaborative planning process with local residents, allowing them to shape the type of education they would receive in the University Center facility. The organisation would be guided by two underlying themes. The first was the public's need for educational opportunities beyond that of a two year college. Residents of the area could not move to another part of the state to continue their education, nor was the political climate amenable to building another institution in the area. The second theme represented a desire by the citizens of the area that their local college demonstrate that it was serving them well. The climate was such that the community was no longer willing to allocate tax dollars to education unless the benefits were very clear. The result was a complex partnership leveraging technology and an integrated organizational structure to serve the residents of northwest Michigan.

\section{THE ORGANISATIONAL FORM OF THE UNIVERSITY CENTER}

\section{Structure}

To improve access and increase intellectual capacity in the region, the planners of the University Center created partnerships with four-year institutions across the state. Improving access was also linked to new technologies that would be capable of creating learning experiences that were highly interactive for the student. The designers of the University Center sought to create a high level of community access and improved cultural quality in the region. This attitude was reflected in the structure of the University Center, which the former President of Northwestern Michigan College said emphasised lean staffing and strong collaboration among educational partners.

The University Center partners (10 public and 2 private colleges or universities) are assembled from throughout the state. The structure reflects a network of institutional representatives around a very small administrative core (see Figure 2). The administrative core is comprised of the dean of the University Center and a small administrative staff. This organisational 


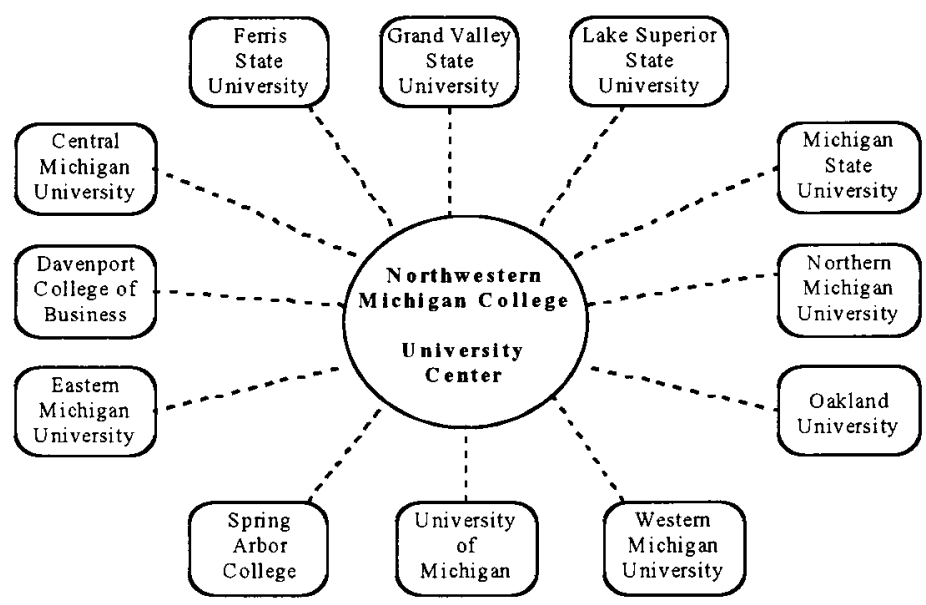

Figure 2. NMC University Center Organisational Structure.

structure allowed a unique group identity to emerge under the University Center umbrella. The relationship between the central organisation of the University Center and its 12 educational partners shows a growing tendency toward identification with the University Center itself, rather than the host institution. Identification with the University Center extended to the students as well.

\section{Strategy}

The former dean expressed a strong belief that raising the intellectual capacity of the individual would then lead to greater economic capacity in the region. This theme was emphasised in the planning report, which noted that per capita wages in the five-county region served by Northwest Michigan College were about 24\% lower than the state average. The balance between responsiveness and dependence was also a key consideration of the management team. The history of the University Center reflects a strong emphasis on community involvement to shape the direction of the centre. Conversely, the University Center was also dependent on the community. As the former dean pointed out, the community rallied around the idea with groups such as high school classes raising money to support the venture.

\section{Processes}

The dean's role was often one of negotiating relationships between partners, though he possessed no formal authority over the institutional representatives that were located at Traverse City. He found that identification 
shifted from the host institution to the central organisation, 'under this umbrella programme of 12 different institutions all having people on site, staff people on site, was allegiance more to the organisation, to this centre, than to their own campuses.' The implications for the new organisation concerning boundary definition appear to rest primarily on negotiating boundaries among the partners, rather than the between the host institution and the central organisation.

\section{Boundary conditions}

Organisations like the University Center have significant implications for faculty work life and boundary management recognition. Increasing efficiency in these organizations in order to meet the demands of the market or community may create more fuzzy boundary conditions. As students increasingly pick and choose courses from a host of institutions to meet their educational needs, the requirement to reduce redundancy in course offerings is likely to arise. Conflict and competition between organisations may lead to infighting, but result in more efficient outcomes. Rules for managing the boundaries between organisations were needed to keep the institutions in check. Specifically, the management team instituted a type of non-competition clause among the universities that stated that they would not offer introductory level courses. The mix of educational partners also led to a combining of the terms education and training, which one informant saw as a trend toward viewing education and training as salable commodities.

\section{Summary}

- The University Center has made the boundaries between citizens of the community and higher education more permeable. Each party has a responsibility in the process.

- Distributed structures and interactive technology eliminate geographic barriers that restrict attendance at four-year institutions.

- Clearly defined non-competition policies among partners create a 'win-win' situation.

- The commodification of knowledge and its causal link to economic advancement in the region (either real or perceived) justifies the value of education offered by the University Center. 


\section{Case Study of Michigan Virtual Automotive College}

\section{Context}

The Michigan Virtual Automotive College (MVAC) is a private, not-forprofit corporation formed by an alliance of the State of Michigan (through the Michigan Jobs Commission), the University of Michigan, Michigan State University, other colleges and universities across the state, and the automotive industry. The organisation exists as a broker or clearinghouse of distance learning services, integrating and marketing the programmes and services of the state's postsecondary institutions for delivery to auto industry employees.

MVAC was initiated as a response to unprecedented changes in the knowledge services required by Michigan automakers (Ford, General Motors and Chrysler) and their suppliers in order to sustain competitive advantages in the global automotive market. The continous education and training needs of auto industry employees at every level - entry-level workers, skilled positions, engineers, and executive management - have necessitated the use of instructional technologies that are flexible and convenient. With nearly 130,000 auto industry employees expected to retire in the next few years, MVAC will largely be responsible for helping the industry educate and train new workers to replace departing employees.

Its World Wide Web Homepage notes that MVAC integrates the 'automotive education and training offerings of Michigan's higher education providers with the support services needed to provide convenient, cost effective, and high-quality automotive education and training.' MVAC researches and assesses employer and employee needs, finds curriculum and technology providers to address those needs, and then assembles participating organisations to deliver the products and services to customers.

\section{Organisational form}

\section{Structure}

MVAC is not so much a single organisation as it is a conglomerate of several organisations converging to deliver knowledge services to its customers. Its fluid structure allows MVAC to reach across boundaries and go directly to the source of information and expertise on different components of the whole education and training package - technology, curriculum, and assessment of industry needs and capabilities. Figure 3 depicts the interrelationships of MVAC with various external partners, including technology providers, course providers, and the automotive industry. The use of dashed lines indicates the permeable boundaries between these entities. 


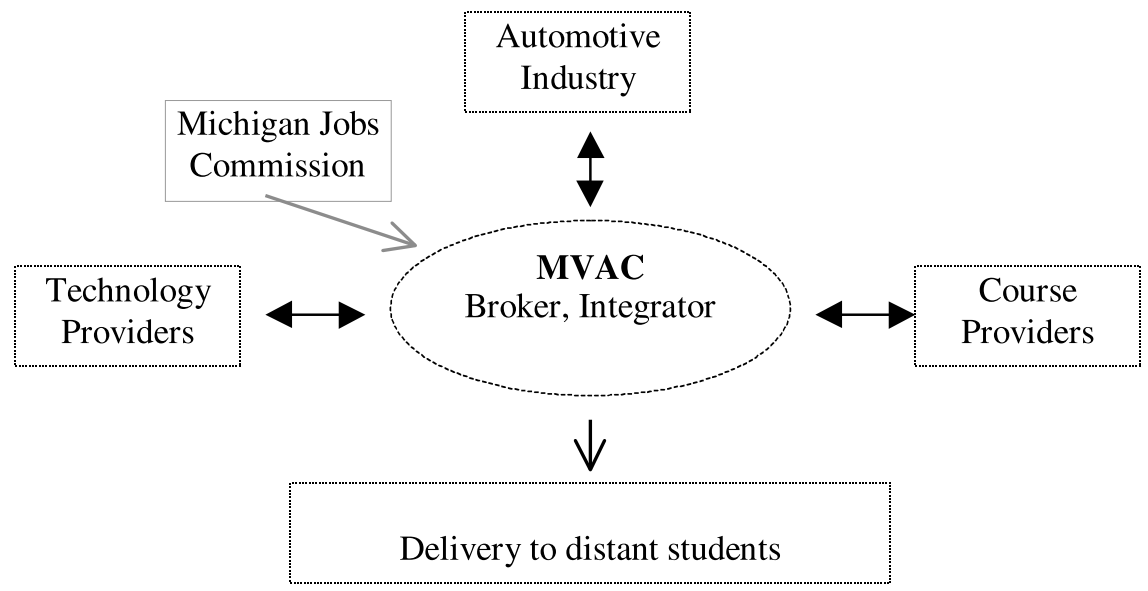

Figure 3. MVAC's interrelationships with key business partners.

MVAC outsources the majority of its various services to private vendors. For example, an outside consulting firm has been retained to research the skill sets of automotive industry employees. Clearly, management takes on a whole new dynamic as MVAC personnel attempt to coordinate the activities and offerings of multiple organisations so that automakers and their suppliers can get the education they need without having to approach the 28 colleges and 14 universities within the state of Michigan on their own.

MVAC's staff members describe the organisational structure as fluid, flat, flexible, lean, quickly adaptable and responsive to client needs. While members admit that in reality the organisation has yet to be tested by client organisations demanding quick responses to changing product or service needs, philosophically, at least, MVAC's structure has been designed to optimise its flexibility in this regard. For example, its collaborative model permits MVAC to substitute new partners as client needs change or as working relationships with contracted partners fail to live up to expectations.

It's adaptability stems in part from the fact that it is not mired in a traditional, inert structure that prohibits fast action and radical redesign when necessary. Organisation members call special attention to the fact that MVAC is not under the control or governance of any one college or university. Respondents uniformly point to the lack of a traditional university bureaucracy and stress that such an arrangement was intentionally planned when the organisation was being conceptualised and designed. 


\section{Strategy}

The most challenging aspect of MVAC's strategy is securing private funding that will enable it to be self-supporting. Given its charge to become financially independent in a relatively short period of time, increased cultivation and solicitation of foundation grant monies are among MVAC's most pressing short-term and long-term strategic objectives.

Another component of its overarching strategy is to build a working model of what entrepreneurial, boundary spanning start-up organisations should look like in the emerging postsecondary knowledge industry. With a host of colleges and universities scrutinising, evaluating and judging MVAC's actions, there is an acute awareness that its successes and failures are public events. Staff members talked about the pressures and challenges of serving as an experimental prototype and the public expectations accompanying its role as an industry example. There is a sense that MVAC's public visibility and its partnership with multiple institutions will act as a stimulus or a catalyst for change at participating colleges and universities or those that observe MVAC. More immediately, the organisation's commercial success may hasten the planning and development of similar ventures in other industrial sectors, such as health care and natural resources.

\section{Processes}

MVAC has frequent and extensive interaction with its various collaborating organisations. There are typically multiple contacts each day with vendors, content providers, policy makers in state government, granting agencies, college presidents, industry clients and partners. The management of relationships with many geographically dispersed partners has become a central activity for MVAC. Client relations, or business development, is a continuous process of networking, pursuing leads, and establishing connections with various organisations.

\section{Boundary conditions}

MVAC serves as an example of a complex, multi-partner collaborative arrangement that has eschewed the establishment of tight boundaries in favour of a more fluid network of highly synergistic relationships. The elaboration of strict territorial boundaries between organisations appears to have little utility in an industry in which providers depend on each other's resources and capabilities to deliver an innovative array of knowledge services. In order for it to succeed in its role as an integrator and coordinator, the boundaries separating MVAC's many constituent organisations and functions must necessarily be transparent or virtually nonexistent. One 
respondent advises simply 'You can't get into this if you think about tight little boundaries.'

\section{Summary}

If the University of Michigan's Academic Outreach Programs is symbolic of the constraints attending entrepreneurial ventures when they are nested within an institutional superstructure, then the Michigan Virtual Automotive College signifies the relative freedom of independent ventures to evolve their own norms, policies and procedures. Its status as an autonomous corporation operating outside the control of established institutions appears to have been a deliberate attempt by its founders and designers to buffer or protect it from the monopoly interest of any one of its partners.

\section{CROSS-CASE THEMES AND IMPLICATIONS}

In this section, we distill the primary themes from our three case studies. We also consider some of the key implications for managers of EBSOs based on our observations.

\section{Permeable boundaries}

Our investigation reveals that the boundaries between organisations in the emerging postsecondary knowledge industry are becoming increasingly difficult to define or identify. The expanding network of partnerships necessary to deliver knowledge services to new customers is seemingly giving rise to an industry standard of highly flexible, permeable boundaries. The Michigan Virtual Automotive College, the University Center, and Academic Outreach would literally cease to exist without the assembly of vendors, content providers, and customers that comprise these ventures. Informants in each of the case study organisations emphasised their dependence on strategic partners for resources, capabilities, and structural organisational features.

\section{Implications}

There are several key management issues attending this flexible boundary structure:

- Managers must direct and coordinate the actions of a geographically dispersed workforce across a variety of industry sectors;

- Managers may need to be particularly sensitive to their staff's need to relate component pieces of projects to an overarching vision or 
strategic direction, especially when participant role clarity is diminished as boundaries between functions, tasks, and activities gradually become less distinct; and

- Increasingly porous boundaries at the interfaces of partnering organisations may evolve distinct social units or autonomous linking systems that develop their own complex structures, routines, norms, loyalties and identities, making it imperative for managers to articulate a unifying sense of purpose.

\section{Emerging organic structures}

The management team of each organisation expressed in different words what we came to believe was a notion of organic or highly adaptable forms of organisational structure within the EBSOs we studied. One informant described the organisational form of his organisation as one built upon the talents and abilities of individuals within the organisation who were hired to play particular roles at particular times. Flexibility was a key component that we observed, and there was understandably little uniformity in the emerging work processes that arose form the organised structure of each of these organisations. Organic organisational structure was also demonstrated through the often elaborate nature of personal contacts that seemed to drive the opportunities, strategy and agenda in some organisations.

\section{Implications}

Based on our observations of the organisations in this study:

- Managers need to attend to the development of trust and team building within their organisations;

- Communicating the thrust of the organisation's mission is imperative;

- The intent of the management team must be clear, so that boundary spanners are able to seize opportunities that present themselves, act decisively and contribute to the organisation as a whole.

\section{The commodification of knowledge}

An often repeated impression of the external environment expressed by the management team of these new organisations is one that incorporates a utilitarian view of knowledge and a customer-focused orientation to the educational service that one should provide. This view is captured in the response of one informant who intimated that traditional colleges and universities lack an understanding that knowledge is a saleable product to be offered in the market place. Other informants spoke of education as a service, in which 'just in time' education that addresses the particular 
needs of individuals, communities and corporations in a timely manner could lead to enhanced economic conditions for citizens of the area. It was very clear that the management team of these organisations held that providing effective knowledge services (the business many felt they we in) is tied to the economy and, as such, organisations of every type in every sector are looking to capitalise on the knowledge capacity they possess, both as customers and suppliers.

\section{Implications}

The view of knowledge as a commodity challenges the notion of knowledge with which traditional educational institutions may be comfortable and suggests the following questions:

- Who are the major competitors, especially those beyond higher education?

- Who will bring about the large scale transformation necessary for meeting the threat of new knowledge competitors, if indeed there are credible competitors to be found?

- How might constituents who are cynical of knowledge as a commodity be convinced that such change is underway?

\section{Affiliation of EBSOs with established institutions}

Our study of EBSOs suggests that these new ventures may confront different challenges, opportunities and issues based on their levels of embeddedness within traditional institutional superstructures. It was clear that the entrepreneurial instincts of $\mathrm{AO}$ were constrained by a conservative university culture. MVAC's position as a private corporation freed it from many of the institutional battles that AO had to fight. The University Center, with its relatively loose structural attachment to Northwestern Michigan College, has enjoyed a sense of independence due to the fact that it represents the implementation of a creative solution to problems of access that could not be met through traditional educational channels.

\section{Implications}

An EBSO's discretion to pursue growth opportunities consistent with its broad objectives may be limited by the venture's relationship to a host institution. Managers may have to devote considerable effort to managing and educating internal constituencies, working within prescribed institutional patterns and keeping the venture squarely on the institutional agenda. Finding pockets of support and adding value to existing operations will be critical. 


\section{Management}

Despite being new organisations, start-up organisations are ambiguous and complex due to the influence of multiple constituencies. They exist in an environment ripe with competitors, including new private, for-profit knowledge providers. They are intended to be lean, flexible organisations. Dynamic individuals who are empowered to take risks and create new paradigms staff them.

\section{Implications}

As such, managing an EBSO requires one to delicately implement strategies that allow the organisation to create new paradigms in higher education while also protecting the organisation from internal and external landmines. Managers must articulate to all staff a common vision of the organisation's objectives on an ongoing basis. It can't be stated on opening day, never to be spoken again. Internally, managers need to continue to foster creativity in individuals but yet emphasise a team-based approach in the organisation. This would allow the organisation to remain dynamic and keep projects interconnected to the mission. Managers must also ensure that there is inter-communication between organisational participants in order to avoid creating an organisation resembling the lanes in a bowling alley.

Managers also need to be aware of expectations, concerns and attitudes of organisations outside their unit. This is especially true given the emerging nature of the knowledge industry. For those EBSOs rooted in an established institution, managers need to be aware of friends and foes alike. Being tied to an institution, rather than being a mostly autonomous organisation, is likely to mean the organisation will evolve more slowly as it manages different levels of interest.

\section{CONCLUSION}

The presence of Academic Outreach, the University Center at Northwestern Michigan College and the Michigan Virtual Automotive College indicate that colleges and universities recognise to at least some degree the opportunities and challenges afforded by participation in the knowledge industry. How institutionalised their participation becomes, and whether participation is a core or peripheral function, remains to be seen. In the meantime, the EBSOs in our sample are leading the way as archetypes. Our study reveals that these new organisational forms possess and seek permeable boundaries with their educational partners and constituents. 
The affiliation of these organisations with established educational organisations could have far reaching effects on the organisational form and boundary conditions of these new ventures. Moreover, management tasks such as coordinating the activities and communicating information to often independent actors can present a significant challenge.

While evidence from our investigation of EBSOs points to a condition of highly flexible boundaries, Ashkenas and his associates (1995) remind us that boundaryless behaviour does not suggest the complete removal of all organisational boundaries. It implies rather that boundaries should be more adaptable or accessible. This view emphasises an organic approach to structuring organisations, allowing information and resources to pass through the organisational membranes in order to reach the critical functions within the organisation. Such a system requires managers to achieve the right degree of permeability for their organisation's boundaries.

As higher education institutions shape and respond to market opportunities and rely increasingly on entrepreneurial organisational forms to deliver knowledge resources to new customers, the role of boundary spanning start-up organisations is likely to become more significant and more prevalent in the 21 st century. The growing interconnectedness of colleges and universities with multiple external entities suggests that these new organisations may be counted on to establish, manage and coordinate vital linkages in an expanding relational network.

\section{REFERENCES}

Ashkenas, R., Ulrich, D., Jick, T. \& Kerr, S. (1995). The Boundaryless Organization. San Francisco, CA: Jossey-Bass Publishers.

Michigan Virtual Automotive College (1997). About MVAC. http://www.mvac.org/ about.html.

Northwestern Michigan College Founders 21 Committee (1993). Report to the Board of Trustees. April 5.

Peterson, M.W. \& Dill, D.D. (1997). Redefining the Postsecondary Knowledge Industry: New Challenges, a New Paradigm and New Planning Perspectives. In M.W. Peterson, D.D. Dill, L.A. Mets \& Associates (eds.), Planning and Management for a Changing Environment: A Handbook on Redesigning Postsecondary Institutions. San Francisco, CA: Jossey-Bass, Inc.

Center for the Study of Higher and Postsecondary Education

University of Michigan

Ann Arbor

Michigan, MI 48109

USA 